\title{
[Azo-Hyd] Tautomerism and Structure of Selected Metal Complex Dyes AM1 and ZIND0/1 Methods
}

\author{
Krzysztof Wojciechowski', Lucjan Szuster ${ }^{2}$ \\ ${ }^{1}$ Institute of Environmental Engineering and Building Installations, Technical University of Łódź, Łódź, Poland \\ ${ }^{2}$ Leather Research Institute, Łódź, Poland \\ Email:krzwojc@p.lodz.pl
}

How to cite this paper: Wojciechowski, K. and Szuster, L. (2016) [Azo-Hyd] Tautomerism and Structure of Selected Metal Complex Dyes AM1 and ZINDO/1 Methods. Computational Chemistry, 4, 97-118. http://dx.doi.org/10.4236/cc.2016.44010

Received: August 27, 2016

Accepted: October 16, 2016

Published: October 19, 2016

Copyright $\odot 2016$ by authors and Scientific Research Publishing Inc. This work is licensed under the Creative Commons Attribution International License (CC BY 4.0).

http://creativecommons.org/licenses/by/4.0/ (c) (i) Open Access

\begin{abstract}
Quantum-chemical calculation methods have been used to examine an influence of tautomeric equilibrium [Azo $\leftrightarrow$ Hydrazo] on a structure of 1:2 chromium metal complex dyes called Gryfalan Navy Blue RL (CI 15 707, Acid Blue 193) and Gryfalan Black RL (Acid Black 194). Chromatographic analysis indicates that synthesis yields a mixture of several dyes with different shades. Studies conducted to date have suggested that such dye complexes can constitute Drew-Pfitzner or Pfeiffer-Schetty structural isomers [1]. It is a know fact, that $o$-hydroxy-azo dyes exist in equilibrium of tautomeric azo and hydrazone forms. We decided to examine, whether color properties of examined metal-complex dyes can be influenced also by an azo-hydrazone equilibrium and what kind of influence on it has sulphonic groups present in molecules. Calculation and optimization of the geometrical structure were performed using the AM1 methods for monoazoo-hydroxy-azo dyesand ZINDO/1 for 1:2 chromium metal complex dyes. It was stated that monoazo dyes can create complexes in both forms: azo and hydrazone, because energy differences between each form of the metal complex dye are so small, that the monoazo dye can, in practice, create complexes in both the azo and the hydrazone form, with energy differences not exceeding about $4-11 \mathrm{kcal} / \mathrm{mol}$. It is calculated that spatial structure changes with an angle of about $90^{\circ}$ between two molecules of the dye, and angles of $10^{\circ}-20^{\circ}$ between the naphthalene moieties. Similar electron density on the hydroxyl and ketone groups suggests that the mixture contains a dominant share of the azo form. The presence of an ionised sulphonic group was also found to affect on the tautomer equilibrium.
\end{abstract}

\section{Keywords}

Acid Dyes, Cr Metal Complexes, Quantum-Chemical Calculations, AM1 and ZINDO/1 Methods 


\section{Introduction}

Attempts at synthesising metal complex dyes have indicated that the metallisation of azo dyes often produces an unevenly coloured mixture. This is especially apparent for such dyes as Acid Blue 193 and Acid Black 194, which are manufactured on a large scale in many countries, including Poland, where they are known as Gryfalan Navy Blue RL (Acid Blue 193, CI 15 707, AB193, CAS No 12392-64-2) and Gryfalan Black RL (Acid Black 194, AB194, CAS No 61931-02-0).

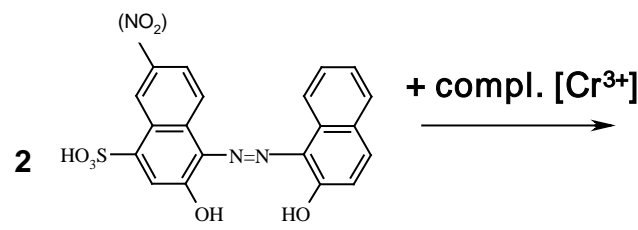

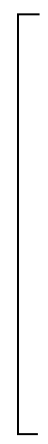

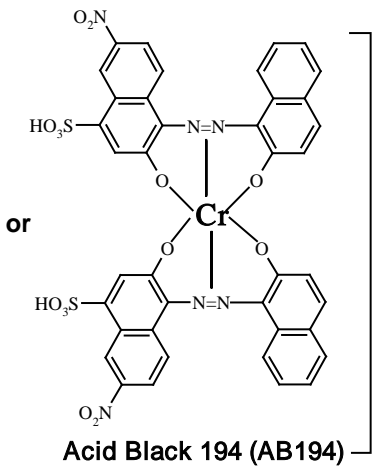

Acid Blue 193 (AB193)

$\mathrm{AB} 193$ and AB194 are 1:2 chromium complexes of a monoazo dye produced by coupling 1,2-diazoxynaphthalene-4-sulphonic acid and 2-naphthol. AB194 is a 6-nitro derivative of the monoazo dye. All commercial AB193 and AB194 dyes contain three components with different values of $\mathrm{R}_{\mathrm{F}}\left(0.46,0.42\right.$, and 0.39; TLC Silica Gel $60 \mathrm{~F}_{254}$ Merck; butyl acetate:propanol:water:acetic acid $=6: 6: 2: 2$ ) and different shades.

Azo dyes make up about $50 \%$ of the volume of all dye types used throughout the world. Among them are metal complex dyes [1], which continue to play a significant role even today thanks to their practical advantages and low price. Over $60 \%$ of all wool is coloured using metal complex dyes. Despite their widespread use and manufacturing history, which dates back to the beginning of the 20th century, their detailed stereochemical structure remains relatively unknown.

Metal complex dyes also owe their importance to the fact that the manufacture of a number of acidic azo dyes has been discontinued due to the carcinogenicity of their substrates or their photochemical or biological decomposition. Dyes produced from carcinogenic or mutagenic amines are being discontinued particularly rapidly.

The aim of this study was to use quantum-chemical methods to investigate the probable structure of monoazo dyes and chromium complexes, taking into account azo-hydrazone tautomerism [A $\leftrightarrow \mathrm{H}$ ], which is typical for $o$-hydroxy-azo derivatives, and to investigate the effect of the sulphonic group and its ionisation on the tautomeric equilibrium [2].

The $\pi$-electrons of metal atoms within intermolecular complexes of organic compounds are transferred as part of conjugated systems. The formation of an intermolecular complex causes a considerable change in electron density, and the incorporation of a metal atom into the conjugated system affects the character of electron transfer in 
the molecule [3].

Complexes with $\mathrm{Cr}^{3+}$ are octahedral and form with the $-\mathrm{OH}$ and $-\mathrm{COOH}$ groups, in which the protons are replaced with the metal ion [4]. As far as the atom of chromium is concerned, the electron configuration $4 s^{1} 3 \mathrm{~d}^{5}$ is more advantageous than the expected $4 s^{2} 3 d^{4}$ configuration. Furthermore, the form of the orbitals changes considerably following excitation or dissociation of the complex [5]. Complexes of this type should create a range of stereoisomers. Zollinger suggests that the $\mathrm{N}_{\alpha \alpha}, \mathrm{N}_{\beta \beta}$, and $\mathrm{N}_{\alpha \beta}$ isomers form with the nitrogen atoms in the $-\mathrm{N}=\mathrm{N}$ - group [1].

Colourimetric analysis indicates that the differences in colour between the analysed dyes stem from the uneven shares of isomers with different spectral characteristics within the mixture, as well as from the fact that the monoazo dye produces various 1:2 chromium complexes [6], [7].

Consequently, any given colouring of a wool fabric is impossible to reproduce once the supplier (the dye manufacturer) changes, since the content of dye isomers differs between suppliers [8].

The reason for this variance in colouring is the method in which the dyes are synthesised and the possible formation of complexes with different spatial structures. The [A $\leftrightarrow$ $\mathrm{H}$ ] equilibrium in monoazo dyes during complexation can also be expected to cause variance in colouring. Theoretical studies have so far not taken into account this issue when explaining the related phenomena.

The synthesis of a dye always results in a mixture of products with different shades and saturations. This may be the result of coupling conditions, specifically, a wide range of $\mathrm{pH}$ (from 7 up to even 12) and metallisation conducted using either pressure-free methods in water or high-pressure methods in water or in a solvent. Because the $\mathrm{Cr}\left(\mathrm{H}_{2} \mathrm{O}\right)_{3}{ }^{3+}$ complexes that take part in the metallisation are stable, the reaction is conducted at a temperature above $90^{\circ} \mathrm{C}[6]$.

The reaction always produces a blue or black dye as the final product, at different yields. Chromatographic analysis indicates that the final product is a mixture. Various modifications to the synthesis method have been proposed. However, no clear conclusions have been reached as to what the optimal conditions for the process are (temperature, ratio of the $\mathrm{Cr}^{3+}$ salt to the monoazo dye, $\mathrm{pH}$, and reaction time) that would lead to a pure, chemically uniform product. Researchers continue to discuss the detailed structure of such complexes in view of the fact that the 1:2 complex can create as many as 11 different spatial structures ( 9 facial Pfeiffer-Schetty configurations and 2 meridial Drew-Pfitzner configurations) [1], [7], [9]-[11] (Figure 1).

In this case, research does not take into account the possible occurrence of monoazo dyes in the hydrazone form, which is the form that $92 \%$ of all $o$-hydroxy-azo dyes assume [12].

The $[\mathrm{A} \leftrightarrow \mathrm{H}]$ tautomerism so far has not been considered as a potential factor affecting the colouring and practical properties of AB193 and AB194. Although many studies point out the role of spatial configuration in 1:2 complexes, they do not associate it with the occurrence of the dye in the azo $(\mathrm{A})$ and hydrazone $(\mathrm{H})$ forms [8]. 

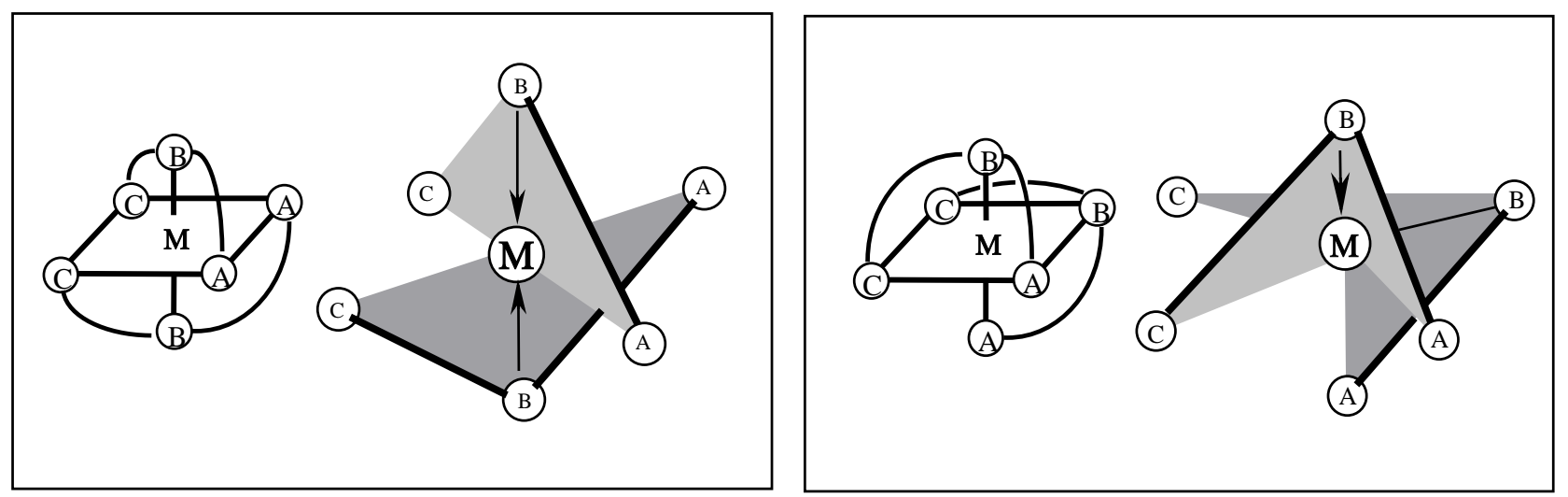

Figure 1. Example of the meridial and facial configuration of a 1:2 complex.

An auxiliary parameter that determines the occurrence probability of $\mathbf{A}$ and $\mathbf{H}$ depending on the presence of substituents is the molecular hardness, $\eta$. Hardness is given by an equation in which the energy values of HOMO and LUMO are obtained using the AM1 method. Hardness is a parametr describing aromaticity of cyclic compounds. Changes of hardness also indicate, that a state of $[\mathrm{A} \leftrightarrow \mathrm{H}]$ equilibrium depending on a presence of substituents in aromatic rings and those changes can be correlated with $\sigma$-Hammetta values of substituents. High hardness means high stability of isomer [13].

Calculations performed using methods similar to ab initio HF/3-21G and HF/6$31 \mathrm{G}^{* *}$ indicated that the calculated limits of azo and hydrazone bond lengths are consistent with statistical values and fall between the two forms. While calculations concerning gaseous molecules are sufficient for many analyses, they provide an incorrect description of the tautomeric equilibrium in solutions [14]. Calculations for the gaseous form provide inaccurate results for a solution, since tautomers have drastically different properties in the gaseous form than those in a solution. The increase in the number of coupled water molecules decreases the H-A energy difference and benefits a stronger stabilisation of the $\mathbf{H}$ form [13], [15].

Calculations performed using the AM1 method suggest that $\mathbf{A}$ is the more stable form of the two. Only when the molecule is made "rigid" can we obtain a form more closely resembling the experimentally determined crystalline form of $\mathbf{A}$ and $\mathbf{H}$, and even then, $\mathbf{A}$ is still more probable in the gaseous state. Calculations performed using the PM5 and COSMO methods concerning the tautomeric equilibrium indicate that the difference in the energy of formation for the tautomers can drop below $20 \mathrm{kcal} / \mathrm{mol}$, in some cases even reaching $<4 \mathrm{kcal} / \mathrm{mol}$, which corresponds to a ratio of tautomers amounting to $>10^{-3}$ at $25^{\circ} \mathrm{C}$. The effects of substituents on azo-hydrazone tautomerism (AHT) depend primarily on solvation energy determined by the presence of the substituents rather than the acceptor character of the substituents [16].

Attempts have been made to develop a synthesis method that would produce a particular, constant concentration of the applied dye and guarantee a constant discharge of heavy metals into wastewater, thus preventing differences in colouring intensity, which currently can reach even $20 \%$ of colouring power. 


\section{Experimental Section}

Quantum-chemical calculations using the AM1 method were performed for monoazo dyes following an optimisation of the molecular structure, which had been conducted using the MM+, DM, and AM1 methods until the lowest value of energy had been reached (convergence limit, 0.01).

Quantum-chemical calculations using the ZINDO/1 method were performed for disazo 1:2 chromium complex dyes following an optimisation of the molecular structure, which had been conducted using the MM+ method until the lowest value of energy had been reached (convergence limit, 0.02).

The calculations were performed with the Hyper Chem v.6.01 software (Hypercube, Inc.). The ZINDO/1 method is a variation of the INDO method, adapted for calculating the electronic properties of metal complex dyes.

Statistical analysis of the results was performed with the Microcal ORIGIN v.6.0 software (Microcal Software, Inc.).

Hardness, $\eta$, which determines the aromatic character of a molecule and the effect of the sulphonic group and its ionisation on the stability of a compound, was calculated based on the following equation [13]:

$$
\eta=\frac{\left[E_{\mathrm{LUMO}}-E_{\text {Hомо }}\right]}{2}
$$

\section{Results}

Experimental data confirm that a mixture of metal complex dyes with different shades and colouring powers is produced. Several hypotheses have been suggested concerning the type of isomerism in the resulting structures; this subject is addressed in [1], [7]. It seemed justified to perform quantum-chemical calculations in order to provide the theoretical grounding for one of these hypotheses.

\section{Tautomeric Equilibrium in Monoazo Dyes}

$O$-hydroxy-azo dyes occur predominantly as a equilibrium between the $\mathrm{A}$ and $\mathrm{H}$ forms, which differ considerably in terms of their properties and colour [14], [17], [18]. Ninety-two per cent of the monoazo dyes that can be found in the Colour Index are in the $\mathbf{H}$ form [12]. The $[\mathrm{A} \leftrightarrow \mathrm{H}$ ] equilibrium depends, among other factors, on substituents, solvents, and temperature.

A rapid exchange of a proton between the tautomers prevents the formation of pure tautomers; the exchange only allows us to determine the tautomerisation constant, $\mathrm{K}_{\mathrm{T}}$, through spectroscopic methods [9]-[11], [14], [19]. The tautomers are assumed to be stable if the energy barrier between them is $>40 \mathrm{kcal} / \mathrm{mol}$, whereas if the energy barrier is $<25 \mathrm{kcal} / \mathrm{mol}$, the tautomers transition between one another [4], [20]. In water, two tautomers may occur if the energy barrier between them, $\Delta \mathrm{H}_{\mathrm{f}}$, is low. In a vacuum, the A form is dominant [17], [21]. In a crystalline state, a mixed crystalline tautomeric form is present [14], [15], [18], [19], [21]. This is suggested by IR measurements, theo- 
retical calculations performed using methods similar to $a b$ initio HF/3-21G and HF/6$31 \mathrm{G}^{* *}[13]$, and the fact that the length of the N-N bond falls between a single bond and a double bond [17].

The $-\mathrm{SO}_{3} \mathrm{H}$ group has a very specific effect on $\mathrm{K}_{\mathrm{T}}$ and changes in enthalpy. This effect is sometimes even greater than that of highly polar substituents, such as the $-\mathrm{CN}$ or -F groups. An especially significant effect is observed when the $-\mathrm{SO}_{3} \mathrm{H}$ group is located in the 2-position relative to the azo group. As long as the former does not cause steric hindrance (the 4-position), the $\mathbf{A}$ form is stabilised more strongly than $\mathrm{H}$ (in naphthol derivatives). The $-\mathrm{SO}_{3} \mathrm{H}$ group favours solvation, to an even greater extent than polar substituents, such as $-\mathrm{NO}_{2}$. Also important is the cation; incorporating it into the calculations provides more accurate information about the energy state of the molecule [16], [22]-[24].

The difficulty in determining the $[\mathrm{A} \leftrightarrow \mathrm{H}]$ equilibrium in sulphonic derivatives lies in the fact that the equilibrium cannot be confirmed through spectral methods, since quantum-chemical calculations have so far been performed for molecules located in a vacuum, and a vacuum makes it impossible to obtain the spectra for sulphonic derivatives [25]. The presence of the $-\mathrm{SO}_{3} \mathrm{H}$ group can also reduce the inclination of the dye to aggregate [6].

Researchers have so far not considered $[\mathrm{A} \leftrightarrow \mathrm{H}$ ] tautomerism as a factor that could affect the colouring and practical properties of AB193 or AB194. Although the latest reports point out the role of spatial configuration in similar 1:2 complexes, they do not associate it with the occurrence of the dye in the $\mathbf{A}$ and $\mathbf{H}$ forms [26]. Our study attempted to determine the effect of $[\mathrm{A} \leftrightarrow \mathrm{H}]$ tautomerism on the structure of $\mathrm{AB} 193$. Similar relationships will also be true for AB194.

\section{Quantum-Chemical Calculations for Monoazo D1 and D2 Dyes Used as Models, Performed with the AM1 Method, and for Their 1:2 $\mathrm{Cr}^{3+}$ Complexes, Performed with the ZINDO/1 Method}

We began with quantum-chemical calculations for dyes used as models that occur only in either the $\mathbf{A}$ or $\mathbf{H}$ form. This helped to greatly simplify the calculations, and additionally allowed us to investigate the role of the sulphonic group, $-\mathrm{SO}_{3} \mathrm{H}$, on the dye equilibrium. The issue is important because under the metallisation conditions, the dye will be in the ionised form, and thus, accepting the assumption makes the calculations more accurate.

\subsection{D1 Dye}

First, we performed calculations for a symmetrical dye, which was a derivative of 2naphthol, and its 1:2 $\mathrm{Cr}^{3+}$ complex, denoted D1 (see in Table 1).

The calculations indicated that the monoazo dye (in Table 2) is more likely to occur in the $\mathbf{H}$ form than the $\mathbf{A}$ form. The calculations did not take into account the effect of solvation caused by the molecules of the solvent, which shifts the equilibrium towards the $\mathrm{H}$ form [17]. 
Table 1. Calculated values of the enthalpy of formation, $E[\mathrm{kcal} / \mathrm{mol}]$, for the azo (A) and hydrazone $(\mathrm{H})$ forms of the $\mathrm{D} 1$ dye used as a model and its 1:2 $\mathrm{Cr}^{3+}$ complex; rotation angles, $\alpha$, of aromatic complexes and molecular hardness, $\eta$.

\begin{tabular}{|c|c|c|c|c|c|c|c|}
\hline Dye & E & $\alpha\left[^{\circ}\right]$ & $\eta$ & Complex & $\Delta \mathrm{E}$ & $\alpha_{1}\left[{ }^{\circ}\right]$ & $\alpha_{2}\left[^{\circ}\right]$ \\
\hline A & -53.156 & 40.4 & 3.644 & $\mathrm{Cr}(\mathrm{AA})$ & 0.859 & 8.6 & 22.5 \\
\hline \multirow[t]{2}{*}{$\mathbf{H}$} & -63.182 & 20.9 & 3.628 & $\mathrm{Cr}(\mathrm{AH})$ & 0.185 & 17.1 & 15.1 \\
\hline & & & & $\mathrm{Cr}(\mathrm{HH})$ & $0.0^{*}$ & 14.9 & 14.4 \\
\hline
\end{tabular}

${ }^{*}-17,516.147 \mathrm{kcal} / \mathrm{mol}$.

Table 2. Electron density of oxygen and nitrogen atoms in amonoazo azo, a derivative of 2naphthol, in the azo $(\mathrm{A})$ and hydrazone $(\mathrm{H})$ forms.

\begin{tabular}{ccccc}
\hline & $\mathrm{O}_{1}$ & $\mathrm{~N}_{1}$ & $\mathrm{~N}_{2}$ & $\mathrm{O}_{2}$ \\
\hline $\mathbf{A}$ & -0.250 & -0.026 & -0.136 & -0.247 \\
$\mathrm{H}$ & -0.266 & 0.015 & $-0.221(\mathrm{NH})$ & $-0.264(\mathrm{OH})$ \\
\hline
\end{tabular}

On the one hand, the obtained results showed that the $\mathrm{H}$ tautomer is highly stable ( $\Delta \mathrm{E}=10.026 \mathrm{kcal} / \mathrm{mol}$ ). On the other, the calculated values of $\eta$ indicate that the monoazo dye is slightly more likely $(\Delta \eta=0.016)$ to occur in the $\mathbf{A}$ form. The calculations were performed for dye molecules in a vacuum. As mentioned above, $\eta$ is an auxiliary parameter that determines the probability of the dye occurring as a particular tautomer.

The energy differences between the $\mathbf{A}$ and $\mathbf{H}$ forms are small enough to allow the monoazo dye to occur in both of them. The boundary amount of energy needed to produce separate tautomers of the compound is $25 \mathrm{kcal} / \mathrm{mol}$. These differences become even lower if the dye creates a 1:2 $\mathrm{Cr}^{3+}$ complex; in such a case, the dye becomes a mixture of three structures with similar energies, the values of which are low enough to allow the mutual transitions to occur as a result of, for instance, only slight changes in reaction energy. However, the most probable structure is $\mathrm{Cr}(\mathrm{HH})$, in which the complex is created with the $\mathrm{H}$ forms of the compound.

\subsection{D2 Dye}

Calculations similar to those for D1 were performed for its symmetrical derivative, the dye model D2, which contained two sulphonic groups. This allowed for an analysis of the role and effect of the sulphonic group on the properties of monoazo dyes and their chromium complexes. Most studies dismiss this effect, as the role of the sulphonic group is limited to adding solubility to the dye molecule, and is assumed not to affect colour or azo-hydrazone equilibrium. While the assumption greatly simplifies calcula- 
tions, it is inaccurate, as the synthesis of a metal complex dye takes place at over $90^{\circ} \mathrm{C}$ in an alkaline environment ( $\mathrm{pH}=7-12)$, in which the $-\mathrm{SO}_{3} \mathrm{H}$ group is an anion. As a result, the group becomes a centre with the highest nucleophilic character, which undergoes solvation extremely easily and can create highly stable salts with the chromium cation or its aquaions. This phenomenon is very undesirable from the environmental standpoint, as it may increase the amount of chromium in post-colouring wastewater beyond the allowable limit of $100 \mathrm{ppm}$.

Our calculations indicate that the sulphonic group has a significant effect on the properties of monoazo dyes. The ionisation of the sulphonic group changes HOMO and LUMO energies, and a hypochromic effect is observed with respect to both the non-ionised form and the monoazo dyes D1 (Figure 2). Furthermore, the values of $\eta$ change. If the sulphonic group is not ionised (Table 3), the $\mathbf{A}$ form should be more stable; otherwise (Table 4), the Hx form should be more stable. This conclusion represents the properties of $o$-hydroxy-azo dyes more accurately. Ionisation also affects the spatial structure of chromium complexes $\left(\alpha_{1}, \alpha_{2}\right)$. Among these, the $\operatorname{Cr}(\mathrm{AH})$ and $\mathrm{Cr}(\mathrm{AxHx})$ complexes, in which the monoazo dyes form a mixture of tautomers, are the most stable.

However, the energy differences, $\Delta \mathrm{E}$, are low enough (only $0.222-0.580 \mathrm{kcal} / \mathrm{mol}$ ) to enable easy transitions between the individual forms of a complex; easier still for complexes with ionised sulphonic groups.

The sulphonic group also affects the electron density of atoms of $\mathrm{O}$ and $\mathrm{N}$ (Table 5 and Table 6). A non-ionised molecule (Table 5) should create a complex with the atoms $\mathrm{O}_{1}, \mathrm{~N}_{1}$, and $\mathrm{O}_{2}$ in the $\mathrm{H}$ form, whereas a molecule containing - $\mathrm{SO}_{3}^{-}$groups should form a complex with the atoms $\mathrm{O}_{1}, \mathrm{~N}_{2}$, and $\mathrm{O}_{2}$ (the monoazo $\mathrm{Hx}$ dye).

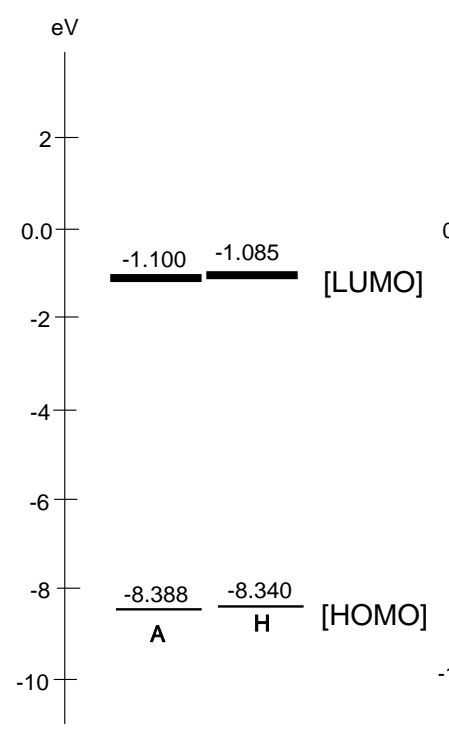

(a)

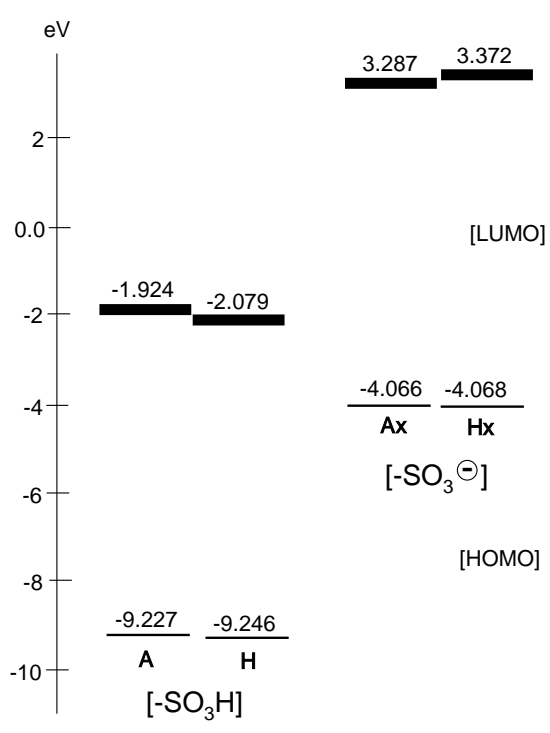

(b)

Figure 2. Values of HOMO and LUMO energy calculated using the AM1 method for (a) the monoazo dye D1 in the azo (A) and hydrazone (H) forms, (b) the monoazo dye D2 in neutral (A and $\mathrm{H}$ ) and anion ( $\mathrm{Ax}$ and $\mathrm{Hx}$ ) forms. 
Table 3. Calculated values of enthalpy of formation, $\mathrm{E}[\mathrm{kcal} / \mathrm{mol}]$, for the azo (A) and hydrazone $(\mathrm{H})$ forms of the $\mathrm{D} 2$ dye used as a model (in the neutral form) and its 1:2 $\mathrm{Cr}^{3+}$ complex; rotation angles, $\alpha$, of aromatic rings and molecular hardness, $\eta$.

\begin{tabular}{|c|c|c|c|c|c|c|c|}
\hline Dye & $\mathrm{E}$ & $\alpha\left[^{\circ}\right]$ & $\eta$ & Complex & $\Delta \mathrm{E}$ & $\alpha_{1}\left[{ }^{\circ}\right]$ & $\alpha_{2}\left[^{\circ}\right]$ \\
\hline $\mathrm{A}\left[\mathrm{SO}_{3} \mathrm{H}\right]$ & -174.548 & 16.7 & 3.652 & $\mathrm{Cr}(\mathrm{AA})$ & 0.580 & 7.4 & 8.7 \\
\hline \multirow[t]{2}{*}{$\mathrm{H}\left[\mathrm{SO}_{3} \mathrm{H}\right]$} & -163.609 & 44.8 & 3.584 & $\mathrm{Cr}(\mathrm{AH})$ & $0.0^{*}$ & 18.6 & 16.0 \\
\hline & & & & $\mathrm{Cr}(\mathrm{HH})$ & 0.522 & 14.9 & 14.0 \\
\hline
\end{tabular}

${ }^{*}-18,017.141 \mathrm{kcal} / \mathrm{mol}$.

Table 4. Calculated values of enthalpy of formation, $\mathrm{E}[\mathrm{kcal} / \mathrm{mol}]$, for the anion forms $\mathbf{A x}$ and $\mathbf{H x}$ of the dye D2 used as a model and its 1:2 $\mathrm{Cr}^{3+}$ complex; rotation angles, $\alpha$, of aromatic rings and molecular hardness, $\eta$.

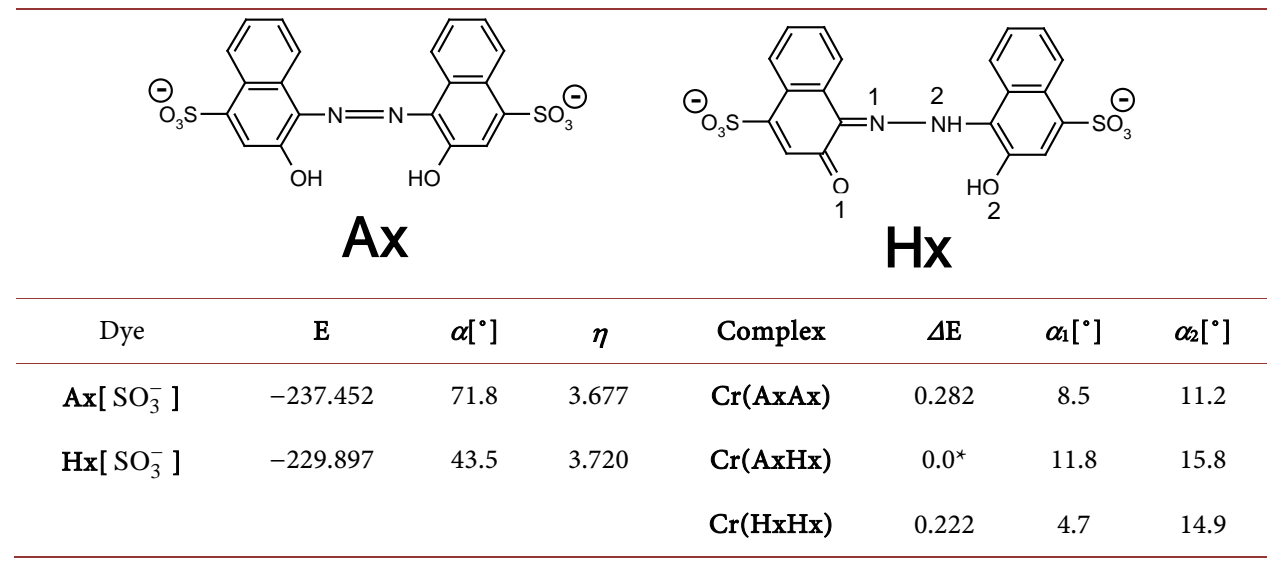

* $-17,290.456 \mathrm{kcal} / \mathrm{mol}$

Table 5. Electron density of oxygen and nitrogen atoms in a monoazo dye, a derivative of 2naphthol-4-sulphonic acid, in the azo $(\mathrm{A})$ and hydrazone $(\mathrm{H})$ forms.

\begin{tabular}{cccccc}
\hline & $\mathrm{O}_{\left(\mathrm{SO}_{3} \mathrm{H}\right)}$ & $\mathrm{O}_{1}$ & $\mathrm{~N}_{1}$ & $\mathrm{~N}_{2}$ & $\mathrm{O}_{2}$ \\
\hline $\mathbf{A}$ & -0.765 & -0.261 & -0.026 & -0.029 & -0.245 \\
$\mathbf{H}$ & -0.767 & -0.454 & -0.240 & $-0.031(\mathrm{NH})$ & $-0.292(\mathrm{OH})$ \\
\hline
\end{tabular}

\subsection{Acid Blue 193 Dye (AB193)}

We optimised the molecule of the dye in the $\mathrm{A}$ form and in two $\mathrm{H}$ forms ( $\mathrm{H} 1$ and $\mathrm{H} 2$ ). While calculations for molecules in a vacuum are sufficient for many analyses, they provide an incorrect description of the tautomeric equilibrium in solutions [14]. The calculations indicate that $\mathbf{A}$ is the more stable form [26]. 
In this study, the structure of the dye was optimised for molecules in a vacuum. However, one should bear in mind that that such calculations are inaccurate if the dye is in a solution, as its tautomers $(\mathrm{A} \leftrightarrow(\mathrm{H} 1$ and $\mathrm{H} 2))$ have drastically different properties in a vacuum than in a solution [8], [15]. The presence of water molecules decreases the A-Henergy difference and benefits a stronger stability of the $\mathrm{H}$ form [15].

An auxiliary parameter that determines the occurrence probability of $\mathbf{A}$ and $\mathbf{H}$ depending on the presence of substituents is molecular hardness, $\eta$. Hardness is given by an equation in which the values of HOMO and LUMO energies are obtained using the AM1 method and denote the aromaticity of a given molecule [13].

In a monoazo dye, the ionization of the sulphonic group $\left(-\mathrm{SO}_{3} \mathrm{H}\right)$ leads to changes in the electron density of the atoms of oxygen $(\mathrm{O})$ and nitrogen $(\mathrm{N})$ in the azo bond. The presence of a non-ionised $-\mathrm{SO}_{3} \mathrm{H}$ group means that the $\mathrm{Cr}^{3+}$ complex should form with the atoms $\mathrm{O}_{1}, \mathrm{O}_{2}$, and $\mathrm{N}_{2}$ in the $\mathbf{A}$ form or with the atoms $\mathrm{O}_{1}, \mathrm{O}_{2}$, and $\mathrm{N}_{1}$ of the $\mathrm{H} 1$ form and the atoms $\mathrm{O}_{1}, \mathrm{O}_{2}$, and $\mathrm{N}_{2}$ in the $\mathrm{H} 2$ form (Table 7). Molecular hardness indicates that the reaction with the $\mathrm{H} 2$ form of the dye is the preferred direction $(\eta=$ 3.641).

During metallisation conducted at a high temperature $\left(>90^{\circ} \mathrm{C}\right)$ and in an alkaline environment, the sulphonic group is ionised (for instance, electron density for the $\mathbf{A}$ form change on oxygen atom from $-0.773\left(\mathrm{SO}_{3} \mathrm{H}\right)$ to $-1.057\left(\mathrm{SO}_{3}^{-}\right)$(Table 7). Because the ionised form of the sulphonic group is also the most probable, it was subjected to calculations using the AM1 method. The ionisation of the $-\mathrm{SO}_{3} \mathrm{H}$ group into $-\mathrm{SO}_{3}^{-}$ changes the electron density on the atoms of oxygen and nitrogen that take part in the formation of the complexes and affects the $[\mathrm{A} \leftrightarrow \mathrm{H}]$ equilibrium.

Table 6. Electron density of oxygen and nitrogen atoms in a monoazo dye, a derivative of 2naphthol-4-sulphonic acid, in the ionised azo $(\mathbf{A x})$ and hydrazone $(\mathbf{H x})$ forms.

\begin{tabular}{cccccc}
\hline & $\mathrm{O}\left(\mathrm{SO}_{3}^{-}\right)$ & $\mathrm{O}_{1}$ & $\mathrm{~N}_{1}$ & $\mathrm{~N}_{2}$ & $\mathrm{O}_{2}$ \\
\hline $\mathbf{A x}$ & -1.064 & -0.263 & -0.144 & -0.026 & -0.263 \\
$\mathrm{Hx}$ & -1.068 & -0.294 & -0.008 & $-0.212(\mathrm{NH})$ & $-0.258(\mathrm{OH})$ \\
\hline
\end{tabular}

Table 7. Electron density of oxygen and nitrogen atoms in amonoazo dye, a derivative of 2naphthol-4-sulphonic acid (AB193) in the azo (A) and hydrazone (H1 and $\mathrm{H} 2)$ forms and in the ionised ( $\mathrm{Ax}, \mathrm{H} 1 \mathbf{x}$, and $\mathrm{H} 2 \mathbf{x})$ forms.

\begin{tabular}{cccccc}
\hline & $\mathrm{O}_{\left(\mathrm{SO}_{3} \mathrm{H}\right)}$ & $\mathrm{O}_{1}$ & $\mathrm{~N}_{1}$ & $\mathrm{~N}_{2}$ & $\mathrm{O}_{2}$ \\
\hline $\mathbf{A}$ & -0.773 & -0.240 & -0.073 & -0.075 & -0.247 \\
$\mathrm{H} 1$ & -0.775 & $-0.243(\mathrm{OH})$ & $-0.195(\mathrm{NH})$ & 0.028 & -0.309 \\
$\mathrm{H} 2$ & -0.773 & -0.254 & 0.001 & $-0.224(\mathrm{NH})$ & $-0.253(\mathrm{OH})$ \\
\hline & $\mathrm{O}\left(\mathrm{SO}_{3}^{-}\right)$ & $\mathrm{O}_{1}$ & $\mathrm{~N}_{1}$ & $\mathrm{~N}_{2}$ & $\mathrm{O}_{2}$ \\
\hline $\mathrm{Ax}$ & -1.057 & -0.257 & -0.172 & -0.018 & -0.258 \\
$\mathrm{H} 1 \mathbf{x}$ & -1.056 & $-0.257(\mathrm{OH})$ & $-0.205(\mathrm{NH})$ & -0.049 & -0.355 \\
$\mathrm{H} 2 \mathbf{x}$ & -1.059 & -0.274 & 0.032 & $-0.190(\mathrm{NH})$ & $-0.252(\mathrm{OH})$ \\
\hline
\end{tabular}


Due to the presence of the $-\mathrm{SO}_{3}^{-}$group, the $\mathrm{A}$ complex should form with the atoms $\mathrm{O}_{1}, \mathrm{O}_{2}$, and $\mathrm{N}_{1}$, whereas $\mathrm{H} 1$ should form with $\mathrm{O} 1, \mathrm{O} 2$, and $\mathrm{N} 1$ and $\mathrm{H} 2$ should form with $\mathrm{O} 1, \mathrm{O} 2$, and $\mathrm{N} 2$ (Table 7). At the same time, the most probable metallisation reaction is one involving the $\mathrm{H} 1 \mathrm{x}$ form, for which $\eta=3.770$, which is over $11 \%$ higher than that of the $\mathbf{A x}$ and $\mathbf{H} 2 \mathbf{x}$ forms and higher than that of the molecules containing a nonionised sulphonic group, i.e., $\mathrm{A}, \mathrm{H1}$, and $\mathrm{H} 2$ (Table 8). Furthermore, the $-\mathrm{SO}_{3}^{-}$group affects the colour of monoazo dyes. As has already been mentioned, the group changes the electron density on $\mathrm{O}$ and $\mathrm{N}$ atoms (Table 7) and the energy of the ground HOMO state and the excited LUMO state. A comparison of $\Delta \mathrm{E}$ values indicates that a bathochromic effect takes place for $\mathbf{A x}$ and $\mathbf{H} 2 \mathbf{x}$ with respect to the analogous forms of a non-ionised dye and a hypsochromic effect takes place for $\mathrm{H} 2 \mathbf{x}$ with respect to $\mathrm{H} 1$ (Figure 3(a)).

However, this only concerns non-solvated structures; the attachment of water molecules to the $\mathrm{N}-\mathrm{NH}, \mathrm{N}=\mathrm{N},-\mathrm{OH}$, or $\mathrm{C}=\mathrm{O}$ groups, changes this state, which may make one of the $\mathrm{H}$ forms dominant in the mixture. These are the conclusions that can be drawn from recently published data [13], [15], [25], [26]. The formation of chromium complexes should result from the formation of bonds with hydroxyl, imine, azo, or carbonyl groups. In such conditions, the molecules of the solvent would not take part in the formation and stabilisation of the $[\mathrm{A} \leftrightarrow \mathrm{H}]$ forms of the dye. Instead, the deciding factor would be the type of (dye-chromium) bonds created during metallisation. The sulphonic groups serve as substituents that change electron density distribution and the energies of the HOMO and LUMO states (Figure 3 and Table 7).

In an ionised molecule, the greatest changes to the HOMO ground state result from the presence of an electronegative substituent, i.e., the $-\mathrm{SO}_{3}^{-}$group (Figure 3).

In our research, we performed calculations for non-solvated molecules and compared the total energies of the 1:2 complexes of the obtained dyes. This simplification is

Table 8. Calculated values of enthalpy of formation, $\mathrm{E}[\mathrm{kcal} / \mathrm{mol}]$, for the $\mathbf{A}, \mathbf{H} 1$ and $\mathrm{H} 2$ forms (in the neutral and ionised forms); rotation angles, $\alpha$, of aromatic rings and molecular hardness, $\eta$.

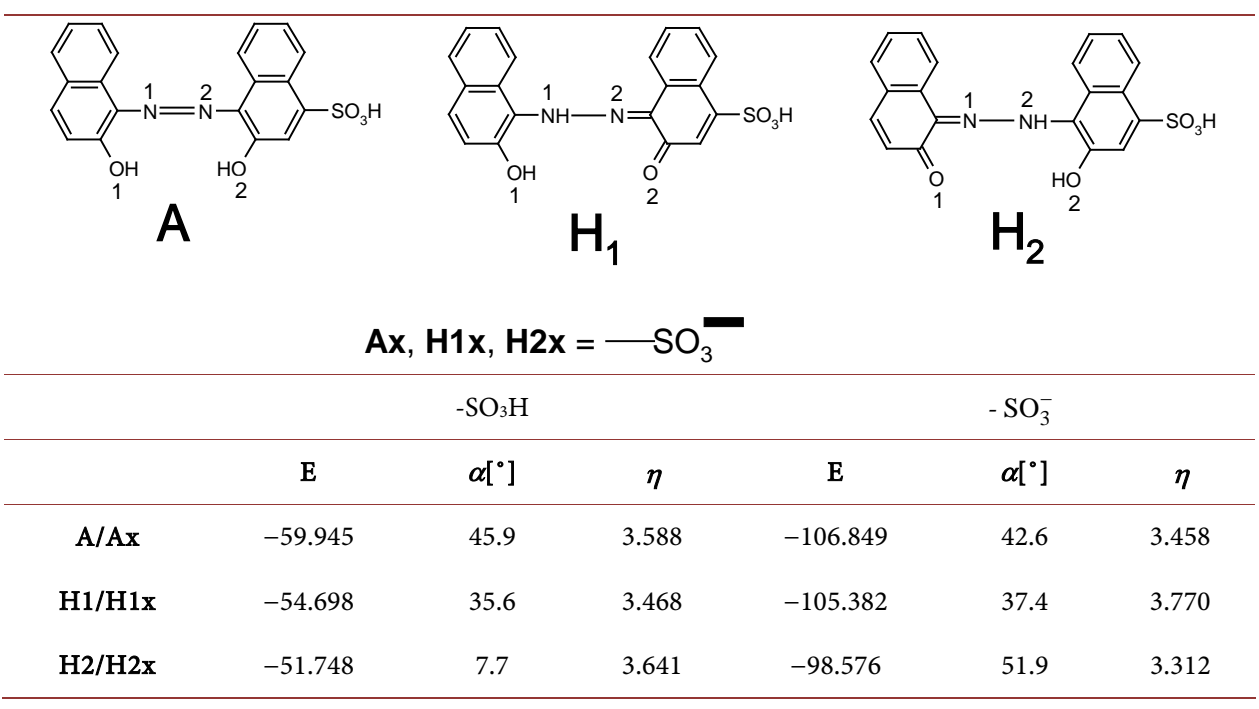




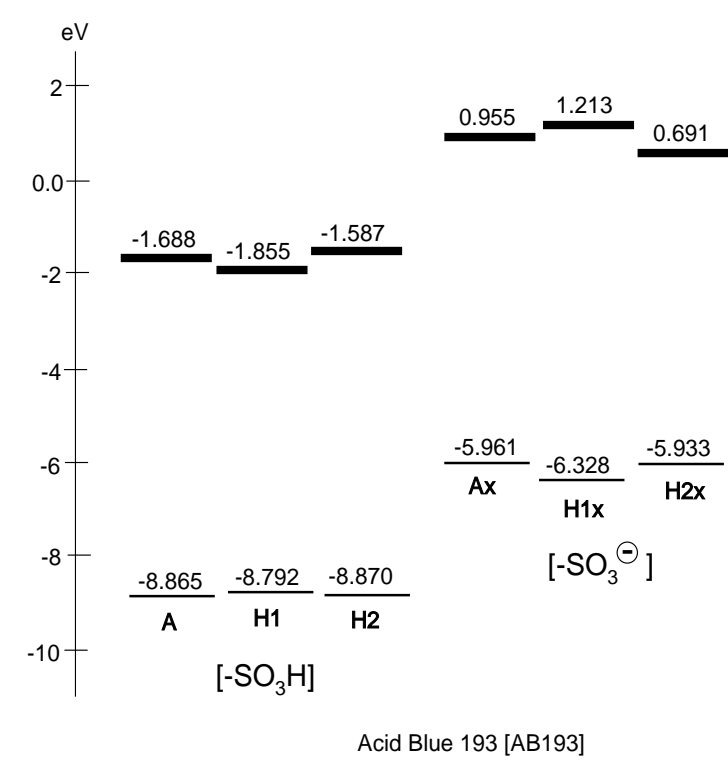

(a)

[LUMO]

[HOMO]

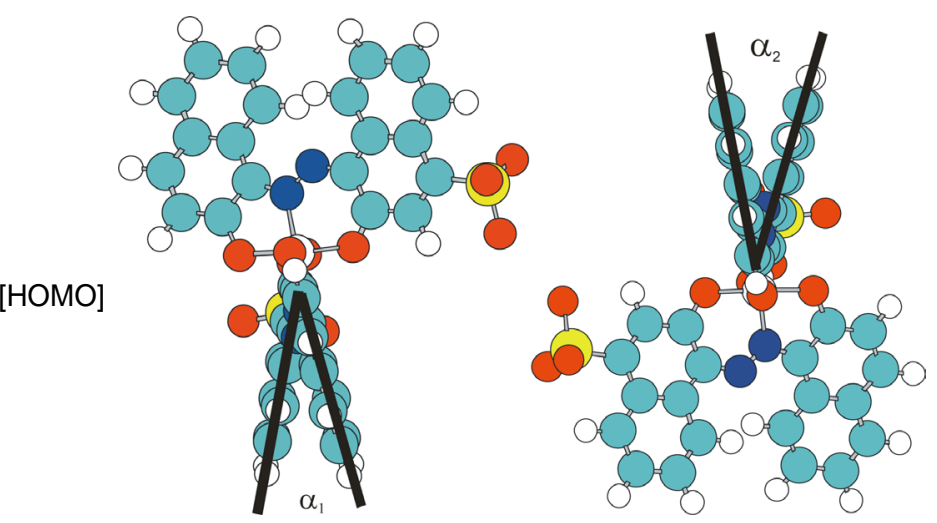

(b)

Figure 3. (a) Differences in HOMO and LUMO energy between monoazo dyes AB193 calculated using the AM1 method for the neutral $\left(-\mathrm{SO}_{3} \mathrm{H}\right)$ and ionised forms $\left(-\mathrm{SO}_{3}^{-}\right)$, (b) rotation angles of the planes of naphthalene rings in the metal complex dye $\mathrm{AB} 193$.

justified, as changes to the tautomeric equilibrium are only likely to occur at the synthesis stage, in a solvent or at a high temperature.

The calculations also took into account the possible formation of $\left[\mathrm{Cr}^{3+}\right.$-azo dye] bonds with the atoms $\mathrm{N}_{\alpha}$ and $\mathrm{N}_{\beta}$ [1]. These complexes would have different energies due to molecular asymmetry, and, consequently, a different distribution of electron density on nitrogen atoms (Table 7) [6], [9].
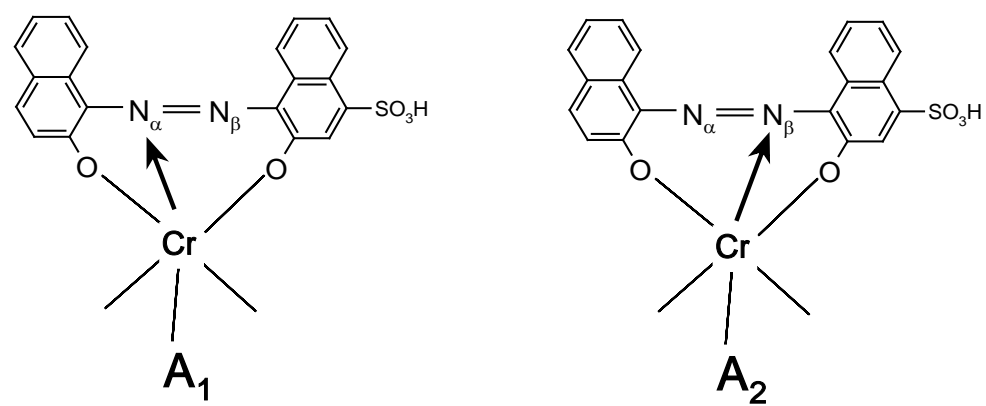

The most probable form is $\mathrm{A} 1 \mathrm{~A} 1$, i.e., the form in which a bond is created between the atoms $\mathrm{N}_{\alpha}$. The calculated values of the enthalpy of formation for a complex indicate that complexes with a bond between $\mathrm{Cr}^{3+}$ and the atoms $\mathrm{N}_{\alpha}$ and $\mathrm{N}_{\beta}$ in the azo bond or $\mathrm{N}_{\beta}$ and $\mathrm{N}_{\beta}$ in molecules containing the $-\mathrm{SO}_{3} \mathrm{H}$ group should be more stable. The ionization of the sulphonic group makes the forms containing $\mathrm{N}_{\alpha}$ and $\mathrm{N}_{\alpha}$ bonds more stable by about $1.4-2.7 \mathrm{kcal} / \mathrm{mol}$ (Table 9 ).

Next, we performed calculations for $\mathrm{Cr}^{3+}$ complexes containing different tautomers of azo dyes (Table 10). For comparison, Table 11 provides the changes in energy for 
Table 9. Example calculated values of enthalpy of formation in a 1:2 complex for neutral $\left(-\mathrm{SO}_{3} \mathrm{H}\right)$ and ionised $\left(-\mathrm{SO}_{3}^{-}\right)$dye molecules.

\begin{tabular}{lcc}
\hline & $-\mathrm{SO}_{3} \mathrm{H}$ & $-\mathrm{SO}_{3}^{-}$ \\
\hline $\mathbf{A}_{1} \mathbf{A}_{1}(\alpha \alpha)$ & $-17,771.6$ & $-17,470.2$ \\
$\mathbf{A}_{1} \mathbf{A}_{2}(\alpha \beta)$ & $-17,772.9$ & $-17,468.8$ \\
$\mathbf{A}_{2} \mathbf{A}_{2}(\beta \beta)$ & $-17,772.9$ & $-17,467.5$ \\
\hline
\end{tabular}

Table 10. Calculated rotation angles of aromatic rings, $\alpha_{1}, \alpha_{2}$, in a 1:2 complex for neutral $\left(-\mathrm{SO}_{3} \mathrm{H} ; \mathrm{A}, \mathrm{H} 1\right.$, and $\left.\mathrm{H} 2\right)$ and ionised $\left(-\mathrm{SO}_{3}^{-} ; \mathbf{A x}, \mathrm{H} 1 \mathbf{x}\right.$, and $\left.\mathrm{H} 2 \mathbf{x}\right)$ dye molecules of the AB193 dye, calculated using the ZINDO/1 method.

\begin{tabular}{|c|c|c|c|c|}
\hline Complex & $\alpha_{1}\left[{ }^{\circ}\right]$ & $\alpha_{2}\left[{ }^{\circ}\right]$ & $\alpha_{1}\left[^{\circ}\right]$ & $\alpha_{2}\left[{ }^{\circ}\right]$ \\
\hline & \multicolumn{2}{|c|}{$\left[-\mathrm{SO}_{3} \mathrm{H}\right]$} & \multicolumn{2}{|c|}{$\left[-\mathrm{SO}_{3}^{-}\right]$} \\
\hline $\operatorname{Cr}(\mathrm{A} 1 \mathrm{~A} 1)$ & 19.2 & 9.8 & 22.4 & 13.1 \\
\hline $\mathrm{Cr}(\mathrm{A} 1 \mathrm{~A} 2)$ & 18.0 & 11.9 & 18.7 & 14.5 \\
\hline $\mathrm{Cr}(\mathrm{A} 2 \mathrm{~A} 2)$ & 18.5 & 14.6 & 18.7 & 14.4 \\
\hline $\mathrm{Cr}(\mathrm{A} 1 \mathrm{H} 1)$ & 9.7 & 10.3 & 17.5 & 10.1 \\
\hline $\mathrm{Cr}(\mathrm{A} 1 \mathrm{H} 2)$ & 17.4 & 10.5 & 17.9 & 13.6 \\
\hline $\mathrm{Cr}(\mathrm{A} 2 \mathrm{H} 1)$ & 17.0 & 10.1 & 17.3 & 11.0 \\
\hline $\mathrm{Cr}(\mathrm{A} 2 \mathrm{H} 2)^{*}$ & 12.5 & 10.5 & 13.9 & 10.9 \\
\hline $\mathrm{Cr}(\mathrm{H} 1 \mathrm{H} 1)^{* *}$ & 13.1 & 13.3 & 19.5 & 10.8 \\
\hline $\mathrm{Cr}(\mathrm{H} 1 \mathrm{H} 2)$ & 17.6 & 17.6 & 19.0 & 13.3 \\
\hline $\mathrm{Cr}(\mathrm{H} 2 \mathrm{H} 2)$ & 18.0 & 13.1 & 21.0 & 10.3 \\
\hline
\end{tabular}

${ }^{*}-17,767.74 \mathrm{kcal} / \mathrm{mol},{ }^{*}-17,464.13 \mathrm{kcal} / \mathrm{mol}$, the most probable structures of the complexes are marked in bold.

Table 11. Differences in the enthalpy of formation, $\Delta \mathrm{H}[\mathrm{kcal} / \mathrm{mol}]$, for the isomers of Acid Blue $\mathrm{RL}$ (AB193) in the azo and hydrazone forms following optimisation using the ZINDO/1 method.

\begin{tabular}{cccccc}
\hline Monoazodye*** & $-\mathrm{SO}_{3} \mathrm{H}$ & $-\mathrm{SO}_{3}^{-}$ & $\mathrm{Dye}$ & $-\mathrm{SO}_{3} \mathrm{H}$ & $-\mathrm{SO}_{3}^{-}$ \\
\cline { 5 - 6 } $\mathrm{A}+\mathrm{A}$ & 0.0 & 0.0 & $\mathrm{Cr}\left(\mathrm{A}_{1} \mathrm{~A}_{1}\right)$ & -2.4 & -0.1 \\
& & & $\mathrm{Cr}\left(\mathrm{A}_{1} \mathrm{~A}_{2}\right)$ & -1.1 & -1.5 \\
& & & $\mathrm{Cr}\left(\mathrm{A}_{2} \mathrm{~A}_{2}\right)$ & $0.0^{*}$ & -2.8 \\
$\mathrm{~A}+\mathrm{H}_{1}$ & -5.7 & -3.7 & $\mathrm{Cr}\left(\mathrm{A}_{1} \mathrm{H}_{1}\right)$ & -3.7 & -4.5 \\
$\mathrm{~A}+\mathrm{H}_{2}$ & -8.1 & -9.7 & $\mathrm{Cr}\left(\mathrm{A}_{1} \mathrm{H}_{2}\right)$ & -1.5 & -3.7 \\
& & & $\mathrm{Cr}\left(\mathrm{A}_{2} \mathrm{H}_{1}\right)$ & -1.1 & -3.9 \\
& & & $\mathrm{Cr}\left(\mathrm{A}_{2} \mathrm{H}_{2}\right)$ & -1.5 & -6.4 \\
$\mathrm{H}_{1}+\mathrm{H}_{1}$ & -13.8 & -13.3 & $\mathrm{Cr}\left(\mathrm{H}_{1} \mathrm{H}_{1}\right)$ & -2.7 & $0.0^{* *}$ \\
$\mathrm{H}_{1}+\mathrm{H}_{2}$ & -11.3 & -7.3 & $\mathrm{Cr}\left(\mathrm{H}_{1} \mathrm{H}_{2}\right)$ & -1.3 & -3.4 \\
$\mathrm{H}_{2}+\mathrm{H}_{2}$ & -16.3 & -19.4 & $\mathrm{Cr}\left(\mathrm{H}_{2} \mathrm{H}_{2}\right)$ & -0.3 & -6.0 \\
\hline
\end{tabular}

${ }^{\star} \mathrm{E}=-17,774.0 \mathrm{kcal} / \mathrm{mol} ;{ }^{* *} \mathrm{E}=-17,470.3 \mathrm{kcal} / \mathrm{mol} ;{ }^{* * *}$ This concerns molecules in a vacuum. 
the tautomers of non-metallised dyes.

In our research, we performed calculations for non-solvated molecules and compared the total energies of 1:2 complexes of the obtained dyes. The most probable form is $\mathrm{Cr}(\mathrm{H} 1 \mathrm{H} 1)$, with an energy of $-17,470.3 \mathrm{kcal} / \mathrm{mol}$, and the least probable form is $\mathrm{Cr}(\mathrm{A} 2 \mathrm{H} 2)$, with energy higher by $6.4 \mathrm{kcal} / \mathrm{mol}$ (Table 11$)$. The latter value is nearly three times lower than $\Delta \mathrm{E}$, at which the tautomers can be separated. A difference this small makes it possible for the two forms to transition between each other under the conditions of the metallisation reaction $\left(>90^{\circ} \mathrm{C}\right)$; hence the mixture of several different-coloured products observed as the product. So far, none of the proposed synthesis methods, despite their variety, has yielded chromatographically pure and applicatively uniform products.

The analysed dyes have a characteristic spatial structure. They always form complexes in which both parts of the dye, i.e., the monoazo dyes, are rotated by an angle of $10^{\circ}-20^{\circ}$ relative to each other, with the $\mathrm{Cr}$ atom connecting the two parts (Figures 3-5).

Calculations were performed for 10 possible complexes for different A (A1 and A2) and $\mathrm{H}$ ( $\mathrm{H} 1$ and $\mathrm{H} 2)$ forms. Table 11 and Figure 6 show the results of the calculations. The energy differences between each postulated form of the metal complex dye change from 0.0 to $-6.4 \mathrm{kcal} / \mathrm{mol}$ (Figure 6, Table 11). Energy barriers this low allow each of the isomers to form during the reaction and enable very easy transitions between them, for instance, during metallisation, which is conducted at high temperatures, ranging

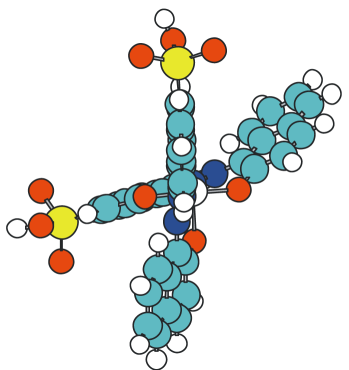

A1A1

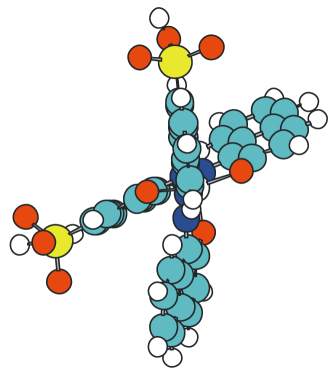

A1A2

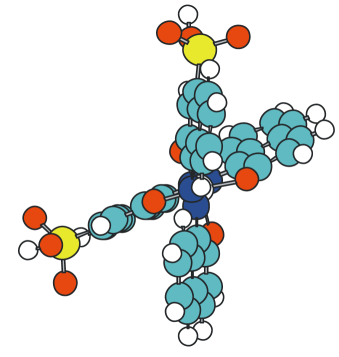

A2A2

Figure 4. Example of a spatial structure of complexes with the neutral azo forms of the dye $\mathrm{AB} 193\left(-\mathrm{SO}_{3} \mathrm{H}\right)$.

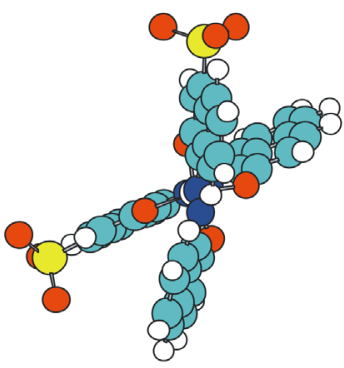

A1xA1x

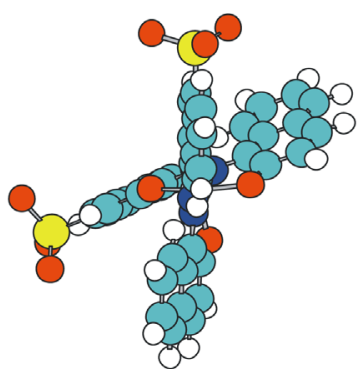

$\mathrm{A} 1 \mathrm{xA} 2 \mathrm{x}$

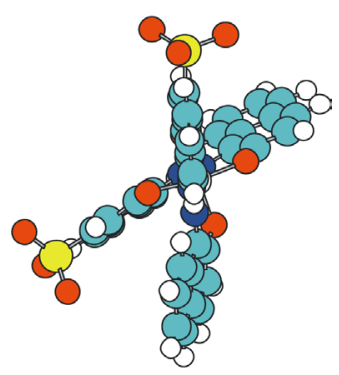

$\mathrm{A} 2 \mathrm{xA} 2 \mathrm{x}$

Figure 5. Example of a spatial structure of complexes with the anion azo forms of the dye AB193 $\left(-\mathrm{SO}_{3} \mathrm{H}\right)$. 
(a)

$\Delta \mathrm{E}[\mathrm{kcal} / \mathrm{mol}]$

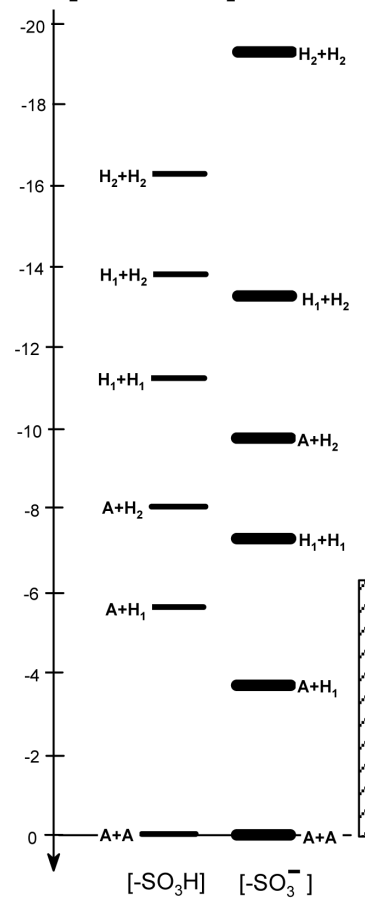

(b)

) 
Practice has shown that the addition of chromium primarily affects the relative intensity and shade of the absorption bands, with only a minor effect on their location [5]. This finding is important for the textile industry, as it means that repeatable colouring is sometimes impossible to achieve.

The formation of a complex containing the $\mathrm{H}$ forms $(\mathrm{H} 1 \mathrm{H} 1)$ is further supported by the high molecular hardness of $\mathrm{H1}$ (Table 8) and its stability in an aqueous solution [13].

\subsection{Acid Black 194 Dye (AB194)}

The AB194 dye, which has important practical applications, was analysed in the same manner as the AB193 dye. AB194 forms similar complexes to AB193 that constitute a mixture of at least three products with different shades. This causes wool fabrics to have different colouring, depending on the dye manufacturer [8]. Even though it has been manufactured and used for over 150 years now, AB194 still suffers from this problem, similarly to AB193.

The structure of the monoazo dye molecule in the $\mathrm{A}, \mathrm{H} 1$, and $\mathrm{H} 2$ forms was optimised for molecules in a vacuum. Furthermore, molecular hardness was calculated using the method described in the Experimental section.

The presence of the $-\mathrm{NO}_{2}$ in monoazo derivatives of $\mathrm{AB} 194$ has a significant effect on the structure of the molecule. For both its non-ionised $\left(\mathrm{A},-\mathrm{SO}_{3} \mathrm{H}\right)$ and ionised $\left(\mathbf{A x},-\mathrm{SO}_{3}^{-}\right)$forms, the dye is more stable in the $\mathbf{A}$ form. A similar effect is observed for AB193. However, analysis of molecular hardness leads to different conclusions, namely, that the $\mathrm{H} 1$ and $\mathrm{H} 2 \mathrm{x}$ tautomers $\left(-\mathrm{SO}_{3}^{-}\right.$) are more probable, for instance in the metallisation reaction (Table 12 and Figure 7). The spatial structure of the tautomers also changes due to the ionisation of the sulphonic group (Figure 7).

Table 12. Calculated values of the enthalpy of formation, $\mathrm{E}[\mathrm{kcal} / \mathrm{mol}]$, of the $\mathbf{A}, \mathbf{H} 1$, and $\mathbf{H} 2$ forms (in the neutral and ionised forms); rotation angles, $\alpha$, of aromatic rings and molecular hardness, $\eta$.
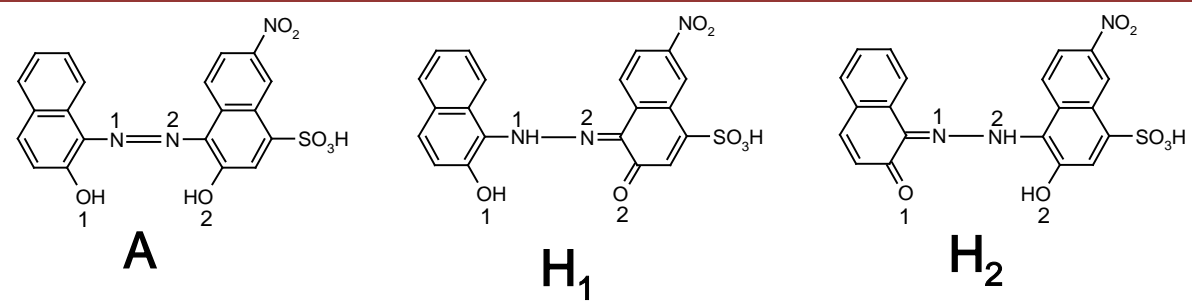

\begin{tabular}{|c|c|c|c|c|c|c|}
\hline \multicolumn{7}{|c|}{$\mathrm{Ax}, \mathrm{H} 1 \mathrm{x}, \mathrm{H} 2 \mathrm{x}=\mathrm{SO}_{3}^{-}$} \\
\hline & \multicolumn{3}{|c|}{$-\mathrm{SO}_{3} \mathrm{H}$} & \multicolumn{3}{|c|}{$-\mathrm{SO}_{3}^{-}$} \\
\hline & $\mathrm{E}$ & $\alpha\left[^{\bullet}\right]$ & $\eta$ & $\mathrm{E}$ & $\alpha\left[^{\circ}\right]$ & $\eta$ \\
\hline $\mathrm{A} / \mathrm{Ax}$ & -53.825 & 39.3 & 3.460 & -108.056 & 66.7 & 3.672 \\
\hline $\mathrm{H} 1 / \mathrm{H} 1 \mathbf{x}$ & -46.861 & 41.9 & 3.693 & -98.296 & 71.9 & 3.567 \\
\hline $\mathrm{H} 2 / \mathrm{H} 2 \mathrm{x}$ & -48.955 & 42.8 & 3.435 & -102.624 & 50.8 & 3.872 \\
\hline
\end{tabular}


Table 13 shows the calculated changes in electron density, $E_{D}$, on the substituents $\left(\mathrm{OH}, \mathrm{NH}\right.$, and $\left.\mathrm{SO}_{3} \mathrm{H}\right)$. The greatest change amounts to about $40 \%$ and is observed on the ionised sulphonic group. Changes also occur on the imine $\mathrm{NH}$ group in the $\mathrm{H}$ tautomer $(\mathrm{H} 1 \mathrm{x})$, where they only amount to about $10 \%$.

On the one hand, the presence of the sulphonic group evens the distribution of the electron density of oxygen and nitrogen atoms in a non-ionised dye (A). On the other hand, the presence of an ionised - $\mathrm{SO}_{3}^{-}$group increases the asymmetry of electron density distribution on the nitrogen atoms in the nitrogen bond. For instance, the value for Ax changes from -0.079 to -0.163 and -0.013 .

The metallisation of monoazo dyes should produce complexes containing primarily the $\mathrm{H} 2 \mathrm{x}$ form, in which the bond $\left[\mathrm{Cr}^{3+}\right.$-dye] is created by the atoms $\mathrm{O}_{1}, \mathrm{O}_{2}$, and $\mathrm{N}_{2}$ (i.e., atoms with the highest electron density), or the $\mathrm{Ax}$ form, in which the bond $\left[\mathrm{Cr}^{3+}\right.$-dye] is created by the atoms $\mathrm{O}_{1}, \mathrm{O}_{2}$, and $\mathrm{N}_{1}$.

Due to the ionisation of the molecule, the greatest changes to the HOMO ground state result from the presence of an electronegative substituent, i.e., the - $\mathrm{SO}_{3}^{-}$group.

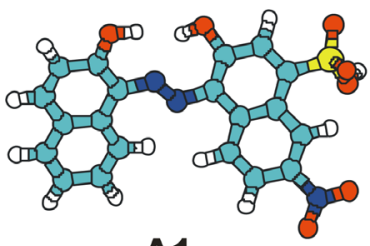

A1

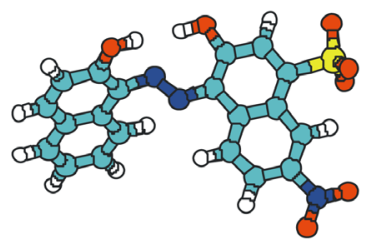

A1x

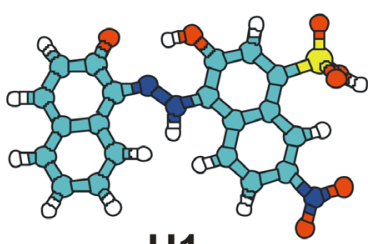

H1

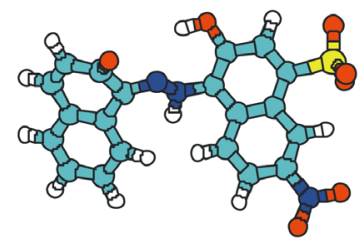

H1x

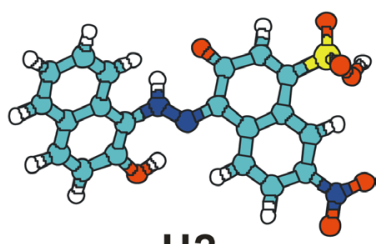

$\mathrm{H} 2$

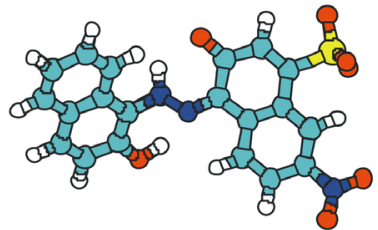

H 2x

Figure 7. Spatial structure of a monoazo 2-naphtol-6-nitro-4-sulphonic acid dye, a derivative of $\mathrm{AB} 194$, in the neutral $\left(-\mathrm{SO}_{3} \mathrm{H} ; \mathrm{A}, \mathrm{H} 1, \mathrm{H} 2\right)$ and ionised $\left(-\mathrm{SO}_{3}^{-} ; \mathrm{Ax}, \mathrm{H} 1 \mathrm{x}, \mathrm{H} 2 \mathrm{x}\right)$ forms.

Table 13. Electron density of oxygen and nitrogen atoms in amonoazo dye, a derivative of 2naphthol-6-nitro-4-sulphonic acid, in the azo (A) and hydrazone (H1 and H2) forms and in the ionised ( $\mathrm{Ax}, \mathrm{H} 1 \mathbf{x}$, and $\mathrm{H} 2 \mathbf{x})$ forms.

\begin{tabular}{cccccc}
\hline & $\mathrm{O}\left(\mathrm{SO}_{3} \mathrm{H}\right)$ & $\mathrm{O}_{1}$ & $\mathrm{~N}_{1}$ & $\mathrm{~N}_{2}$ & $\mathrm{O}_{2}$ \\
\hline $\mathbf{A}$ & -0.767 & -0.237 & -0.079 & -0.079 & -0.242 \\
$\mathrm{H} 1$ & -0.764 & $-0.240(\mathrm{OH})$ & $-0.179(\mathrm{NH})$ & 0.050 & -0.315 \\
$\mathbf{H} 2$ & -0.765 & -0.246 & -0.025 & $-0.212(\mathrm{NH})$ & $-0.235(\mathrm{OH})$ \\
\hline & $\mathrm{O}\left(\mathrm{SO}_{3}^{-}\right)$ & $\mathrm{O}_{1}$ & $\mathrm{~N}_{1}$ & $\mathrm{~N}_{2}$ & $\mathrm{O}_{2}$ \\
\hline $\mathbf{A x}$ & -1.050 & -0.255 & -0.163 & -0.013 & -0.249 \\
$\mathbf{H} 1 \mathbf{x}$ & -1.053 & $-0.258(\mathrm{OH})$ & $-0.198(\mathrm{NH})$ & -0.003 & -0.361 \\
$\mathbf{H} 2 \mathbf{x}$ & -1.052 & -0.264 & 0.041 & $-0.209(\mathrm{NH})$ & $-0.245(\mathrm{OH})$ \\
\hline
\end{tabular}


These changes are similar to those observed for AB193.

The presence of the $-\mathrm{NO}_{2}$ group also affects the stability of chromium complexes. The most stable isomer was $\mathrm{Cr}(\mathrm{H} 1 \mathrm{xH} 2 \mathrm{x})$, and the least stable isomer was $\mathrm{Cr}(\mathrm{A} 2 \mathrm{xH} 2 \mathrm{x})$, with a difference of $10.08 \mathrm{kcal} / \mathrm{mol}$ between the two. As with $\mathrm{Ab} 193$, the angles $\alpha_{1}$ and $\alpha_{2}$ change in comparison to the non-ionised dyes (Table 14).

The difference in the enthalpy of formation for complexes with nitro derivatives, $\Delta \mathrm{H}$, is also (as with $\mathbf{A B 1 9 3}$ ) lower than the stability boundary for $\mathbf{A}$ and $\mathrm{H}$ tautomers ( $\mathrm{H} 1$ and H2) of the $o$-hydroxy-azo dyes. Therefore, it may be assumed that the structure of the molecules may change during the metallisation reaction, depending on the conditions under which the reaction takes place. For monoazo dyes (Table 12), $\Delta \mathrm{E}$ amounts to $6-10 \mathrm{kcal} / \mathrm{mol}(\mathrm{Ax}, \mathrm{H} 1 \mathbf{x}$, and $\mathrm{H} 2 \mathbf{x})$ and is higher than for the derivatives of $\mathrm{AB} 193$, for which the corresponding differences amount to $1-8 \mathrm{kcal} / \mathrm{mol}$. However, contrary to $\mathrm{AB} 193$, ionised monoazoAB194 dyes should display a hypsochromic effect relative to non-ionised molecules. The $\Delta \mathrm{E}_{\text {[номо-LUмо] }}$ differences amount to $7.34-7.83 \mathrm{kcal} / \mathrm{mol}$ for the ionised dyes and to $6.87-7.38 \mathrm{kcal} / \mathrm{mol}$ for the non-ionised dyes (Figure 8).

In our research, we performed calculations for non-solvated molecules and compared the total energies of the 1:2 complexes of the obtained dyes. The most probable form is $\mathrm{H} 1 \mathrm{xH} 2 \mathrm{x}$ for the ionised molecules and $\mathrm{H} 1 \mathrm{H} 1$ for the non-ionised molecules.

Figure 9 shows the energy differences between metal complex dyes in which the monoazo can occur as various tautomers. The most probable dye complexes are those that involve the $\mathrm{H}$ forms (except for $\mathrm{A} 1 \mathrm{H} 1$ ) of nitro derivatives during formation. At the same time, the calculations indicate that comparing the properties of structurally very similar dyes such as AB193 and AB194 may be burdened with a considerable error.

Table 14. Differences in the enthalpy of formation $\Delta \mathrm{E}[\mathrm{kcal} / \mathrm{mol}]$ in a $1: 2$ complex for neutral $\left(-\mathrm{SO}_{3} \mathrm{H} ; \mathbf{A}, \mathrm{H} 1\right.$, and $\mathrm{H} 2$ ) and ionised $\left(-\mathrm{SO}_{3}^{-} ; \mathrm{Ax}, \mathrm{H} 1 \mathbf{x}\right.$, and $\left.\mathrm{H} 2 \mathbf{x}\right)$ molecules of the AB194 dye; rotation angles of naphthalene rings relative to one another (Figure 8 and Figure 9).

\begin{tabular}{|c|c|c|c|c|c|c|c|}
\hline Complex $\mathrm{Cr}$ & $\Delta \mathrm{E}$ & $\alpha_{1}\left[{ }^{\circ}\right]$ & $\alpha_{2}\left[{ }^{\circ}\right]$ & Complex Cr & $\Delta \mathrm{E}$ & $\alpha_{1}\left[{ }^{\circ}\right]$ & $\alpha_{2}\left[^{\circ}\right]$ \\
\hline \multicolumn{5}{|c|}{$\left[-\mathrm{SO}_{3} \mathrm{H}\right]$} & \multicolumn{3}{|c|}{$\left[-\mathrm{SO}_{3}^{-}\right]$} \\
\hline A1A1 & 10.32 & 11.8 & 22.2 & $\mathrm{~A} 1 \mathrm{xA} 2 \mathrm{x}$ & 7.41 & 12.6 & 21.4 \\
\hline $\mathrm{A} 1 \mathrm{~A} 2$ & 8.33 & 16.9 & 17.5 & $\operatorname{A} 1 x A 2 x$ & 7.94 & 8.5 & 18.1 \\
\hline $\mathrm{A} 2 \mathrm{~A} 2$ & 9.04 & 12.4 & 14.5 & $A 2 x A 2 x$ & 8.04 & 18.0 & 12.5 \\
\hline A1H1 & 8.24 & 12.9 & 15.8 & AlxH1x & 0.50 & 19.1 & 13.5 \\
\hline $\mathrm{A} 1 \mathrm{H} 2$ & 10.82 & 16.9 & 10.9 & $\mathrm{~A} 1 \mathrm{xH} 2 \mathrm{x}$ & 7.91 & 18.5 & 8.2 \\
\hline $\mathrm{A} 2 \mathrm{H} 1$ & 7.24 & 14.1 & 13.3 & $\mathrm{~A} 2 \mathrm{xH} 1 \mathrm{x}$ & 9.49 & 15.0 & 14.7 \\
\hline $\mathrm{A} 2 \mathrm{H} 2$ & 7.95 & 27.5 & 12.6 & $\mathrm{~A} 2 \mathrm{xH} 2 \mathrm{x}$ & 10.08 & 10.2 & 20.4 \\
\hline $\mathrm{H} 1 \mathrm{H} 1$ & $0.0^{*}$ & 16.4 & 17.8 & $\mathrm{H} 1 \mathrm{xH} 1 \mathrm{x}$ & 2.48 & 19.4 & 8.1 \\
\hline $\mathrm{H} 1 \mathrm{H} 2$ & 1.59 & 15.3 & 18.0 & $\mathrm{H} 1 \mathrm{xH} 2 \mathrm{x}$ & $0.0^{* *}$ & 14.2 & 13.8 \\
\hline $\mathrm{H} 2 \mathrm{H} 2$ & 4.04 & 12.5 & 13.1 & $\mathrm{H} 2 \mathrm{xH} 2 \mathrm{x}$ & 0.37 & 13.2 & 9.4 \\
\hline
\end{tabular}

${ }^{*} \mathrm{E}=-18,632.22 \mathrm{kcal} / \mathrm{mol},{ }^{* *} \mathrm{E}=-18,350.32 \mathrm{kcal} / \mathrm{mol}$. 


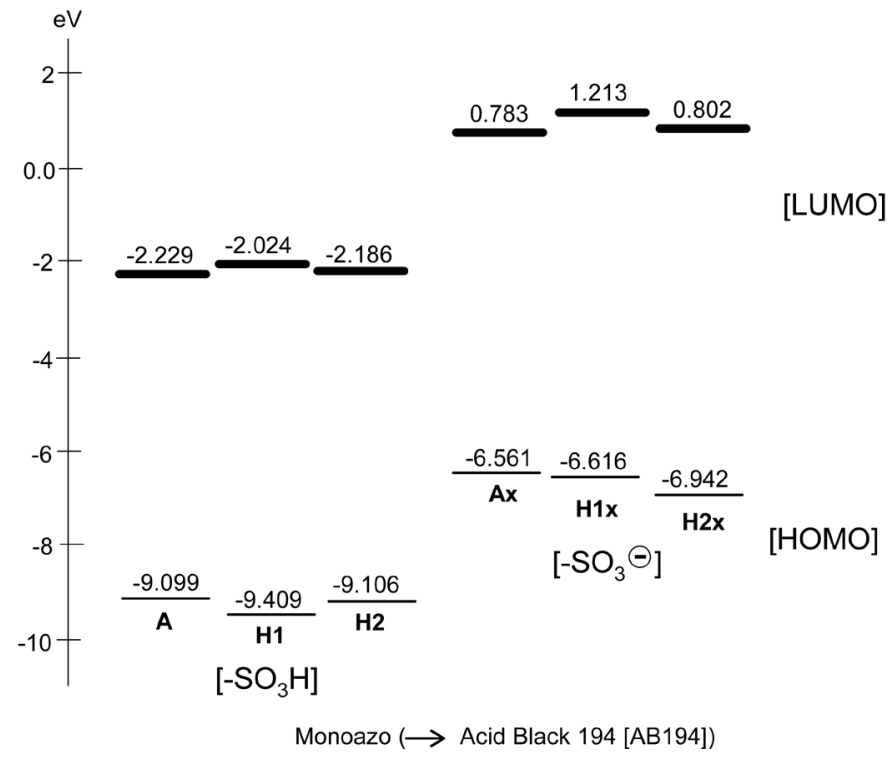

Figure 8. Differences in HOMO and LUMO energies of the monoazo dyes AB194 calculated using the AM1 method in the neutral $\left(-\mathrm{SO}_{3} \mathrm{H}\right)$ and ionised $\left(-\mathrm{SO}_{3}^{-}\right)$forms.

(a)

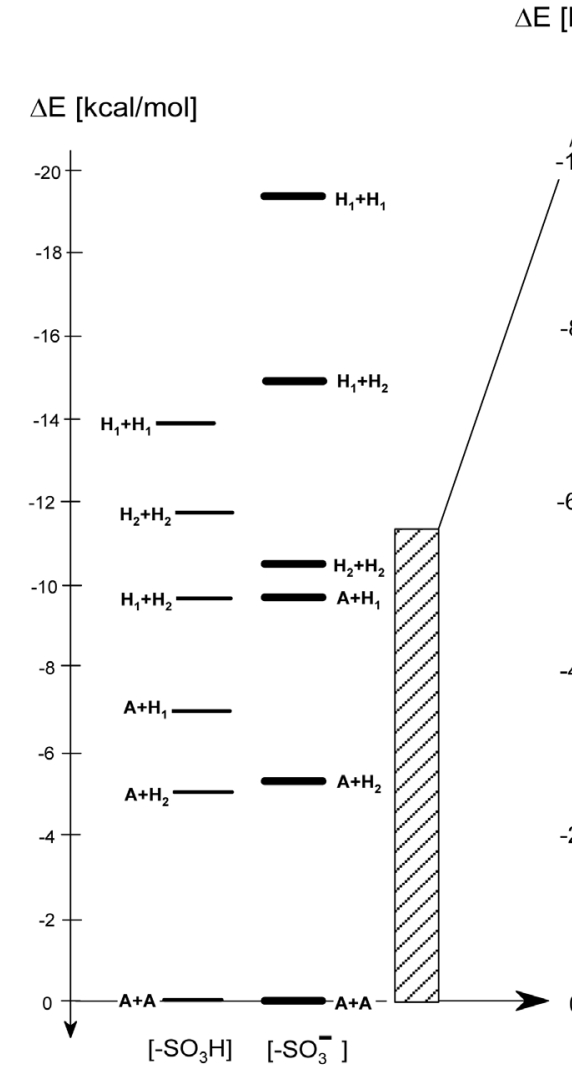

(b) $\Delta \mathrm{E}[\mathrm{kcal} / \mathrm{mol}]$

Figure 9. Differences in the enthalpy of formation $\Delta \mathrm{E}[\mathrm{kcal} / \mathrm{mol}]$ of $\mathrm{AB} 194$ isomers in the azo (A and $\mathbf{A x}$ ) and hydrazone ( $\mathrm{H} 1, \mathrm{H} 2, \mathrm{H} 1 \mathbf{x}$, and $\mathrm{H} 2 \mathbf{x}$ ) forms; (a) energy differences between monoazo dyes calculated using the AM1 method; (b) energy differences between 1:2 metal complex dyes following optimisation using the ZINDO/1 method.
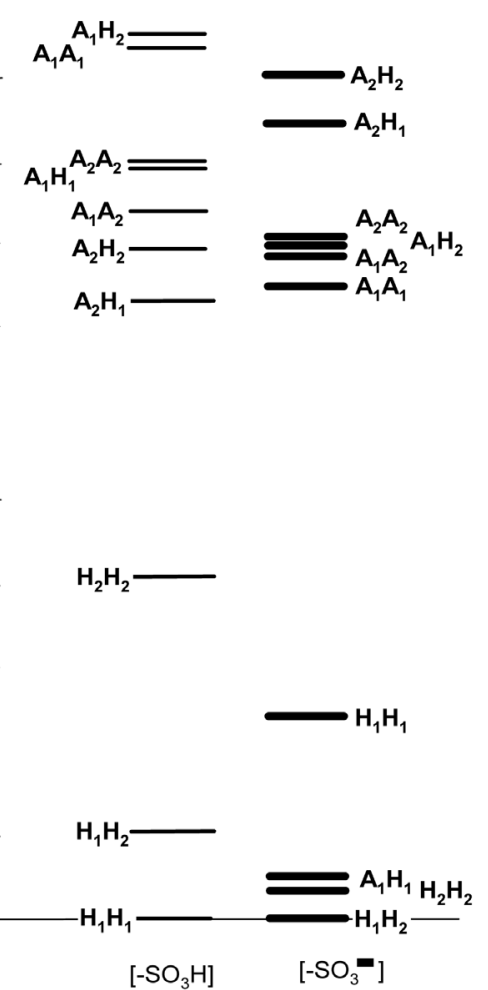


\section{Conclusions}

For the first time, a tautomeric equilibrium in 1:2 chromium metal complex dyes has been examined using quantum-chemical calculation.

Calculations were performed concerning the electron structure of the tautomers of monoazo dyes, their chromium complexes, AB193 and AB194, and compounds used as models, D1 and D2.

The calculations indicate that the energy differences between the individual isomers are low enough to allow the forms to transition between one another under the conditions of the metallisation reaction $\left(>90^{\circ} \mathrm{C}\right)$. As a result, a mixture of several products with different colours is obtained. It explains why regardless of the proposed synthesis methods, despite their variety, chromatographically pure and applicatively uniform products are not being created.

The performed calculations indicate that $\mathrm{H} 1 \mathrm{H} 1$ is the most probable form, as supported, on the one hand, by the stability of the $\mathrm{H} 1 \mathrm{form}$, which is stable in a vacuum ("hardness" $\eta$ ), and, on the other hand, the experiential finding that $o$-hydroxy-azo dyes occur primarily in the $\mathrm{H}$ form, especially under conditions that enable the solvation of the dye molecule. Similar electron density on the hydroxyl and ketone groups suggests that the mixture contains a dominant share of the azo form. The presence of an ionised sulphonic group was also found to affect on the tautomer equilibrium.

The ZINDO/1 quantum-chemical method used in the calculations is the only one within the Hyper Chem package that allows parameterisation for metals; and even though the applied procedure is simplified (a variant of the INDO method), the obtained results shed new light on the structure of 1:2 chromium complexes and the actual state of their molecules, which has been indirectly confirmed by experimental research and the conclusions drawn from it.

\section{References}

[1] Zollinger, H. (1991) Colour Chemistry. Wiley-VCH, Weinheim.

[2] You, W., Zhu, H.-Y., Huang, W., Hu, B., Fan, Y. and You, X.-Z. (2010) The First Obserwation of Azo-Hydrazone and Cis-Trans Tautomerisms for Disperse Yellow Dyes and Their Nickel(II) and Copper(II) Complexes. Dalton Transactions, 39, 7876-7880. http://dx.doi.org/10.1039/c0dt00101e

[3] Gordon, P.F. and Gregory, P. (1983) Organic Chemistry in Color. Springer-Verlag, Berlin.

[4] Price, R. (1971) In: Venkataraman, K., Ed., The Chemistry of Synthetic Dyes, Vol. 3, Academic Press, New York, 302.

[5] McWeeny, R. (1979) Coulson's Valence. 3rd Edition, Oxford University Press, Oxford.

[6] Antonov, L., Gergov, G., Petrov, V., Kubista, M. and Nygren, J. (1999) UV-Vis Spectroscopic and Chemometric Study on the Aggregation of Ionic Dyes in Water. Talanta, 49, 99106. http://dx.doi.org/10.1016/S0039-9140(98)00348-8

[7] Schetty, G. (1970) Neuartige Isomeriefälle bei 1:2-Cr${ }^{\mathrm{III}}$-und $\mathrm{Co}^{\mathrm{III}}$-Komplexen von o, $o$-Dihydroxyazoverbindungen: Pyramidal gebundener Stickstoff mit hoher Inversionsbarriere? Helvetica Chimica Acta, 53, 1437-1459. http://dx.doi.org/10.1002/hlca.19700530627

[8] Wojciechowski, K., Szuster, L., Rutowicz, J. and Kaminska, A. (2014) Dyeing Properties of 
Acid Blue 193 and Non-Equivalent Properties of CI Acid Black 194 Produced by Different Manufacturers. Coloration Technology, 130, 215-220. http://dx.doi.org/10.1111/cote.12084

[9] Shorein, J. (1999) Colorant and Auxiliarities. Organic Chemistry and Application Properties. Vol. 1, Society of Dyers and Colourists, Bradford, 196.

[10] Coates, E. and Rigg, B. (1962) Some Physico-Chemical Properties of Solochrome Violet R and Its Metal Complexes. Journal of the Society of Dyers and Colourists, 78, 612-619. http://dx.doi.org/10.1111/j.1478-4408.1962.tb02472.x

[11] Venkataraman, K. (1971) The Chemistry of Synthetic Dyes. Vol. 3, Academic Press, New York, 167. (Russ Translation)

[12] CI (Colour Index) (1971) Chemical Constitutions. 3rd Edition, Society of Dyersand Colourists (SDC) and American Association of Textile Chemists and Colourists (AATCC).

[13] Antonov, L.M. (1996) 31 UNESCO Course for Advances Research in Chemistry and Chemical Engineering, Tokyo Institute of Technology.

Majerz, I. and Diembowska, T. (2011) Geometric Aspects of Aromaticity: Interrelations between Intramolecular Hydrogen Bonds, Steric Effects and $\pi$-Electron Delocalisation in Nitroanilines. European Journal of Inorganic Chemistry, 2011, 280-286.

http://dx.doi.org/10.1002/ejoc.201000978

Krygowski, T.M., Stępień, B.T. and Cyrański, M.K. (2005) Energetic Aspects of Cyclic Pi-Electron Delocalization: Evaluation of the Methods of Estimating Aromatic Stabilization Energies. International Journal of Molecular Sciences, 6, 45-51.

http://dx.doi.org/10.1021/cr0300845

Cyrański, M.K. (2005) How the Substituent Effect Influences $\pi$-Electron Delocalisation in the Ring of Reactants in the Reaction Defining the Hammett Substituent Constants om and op. Chemical Reviews, 105, 3773-3811. http://dx.doi.org/10.3390/i6010045

[14] Antonov, L. and Stoyanov, S. (1995) Azo-Quinonehydrazone Tautomerism in 2-Phenylazo1-Naphthol. Dyes and Pigments, 28, 31-39. http://dx.doi.org/10.1016/0143-7208(94)00076-E

[15] Antonov, L., Kawauchi, S., Satoh, M. and Komijama, J. (1999) Theoretical Investigations on the Tautomerism of 1-Phenylazo-4-Naphthol and its Isomers. Dyes and Pigments, 40, 163. http://dx.doi.org/10.1016/S0143-7208(98)00044-8

[16] Iijima, T., Jojima, E., Antonov, L., Stoyanov, S. and Stoyanov, T. (1998) Aggregation and Tautomeric Properties of CI Acid Red 138. Dyes and Pigments, 37, 81-92. http://dx.doi.org/10.1016/S0143-7208(97)00042-9

[17] Kelemen, J., Kormany, G. and Rihs, G. (1982) Azo-Hydrazone Tautomerism in Azo Dyes. III. The Tautomeric Structure of Adsorbed 1-(4'-Nitrophenylazo)-2Naphthylamine from Crystal Structure Determination. Dyes and Pigments, 3, 249-271. http://dx.doi.org/10.1016/0143-7208(82)80001-6

[18] Lyčka, A. and Macháček, V. (1986) ${ }^{13} \mathrm{C}$ and ${ }^{15} \mathrm{~N}-\mathrm{NMR}$ Studies of the Azo-Hydrazonetautomerism of Some Azo Dyes. Dyes and Pigments, 7, 171-185. http://dx.doi.org/10.1016/0143-7208(86)85008-2

[19] Antonov, L. and Stoyanov, S. (1995) Resolution of Overlapping UV-Visible Absorption Bands: Quantitative Analysis of Tautomeric Equilibria. Analytica Chimica Acta, 314, 225 232. http://dx.doi.org/10.1016/0003-2670(95)00281-4

[20] Elguero, J., Katritzky, A.R. and Denisenko, O.V. (2000) Prototropictautomerism of Heterocycles: Heteroaromatictautomerism-General Overview and Methodology. ChemInform, 76, 1-84.

[21] Morgan, K.J. (1961) Infrared Spectra and Structure of Arylazonaphthols. Journal of the 
Chemical Society, 1961, 2151-2159. http://dx.doi.org/10.1039/jr9610002151

[22] Hikara, T., Okada, Y. and Morita, Z. (2003) Azo-Hydrazonetautomerism of Phenylazonaphthol Sulfonates and Their Analysis Using the Semiempirical Molecular Orbital PM5 Method. Dyes and Pigments, 59, 25-41. http://dx.doi.org/10.1016/S0143-7208(03)00093-7

[23] Wojciechowski, K. and Szadowski, J. (2000) Effect of the Sulphonic Group Position on the Properties of Monoazo Dyes. Dyes and Pigments, 44, 137-147. http://dx.doi.org/10.1016/S0143-7208(99)00085-6

[24] Lyčka, A. and Holeček, J. (2003) ${ }^{15} \mathrm{~N},{ }^{13} \mathrm{C}$ and ${ }^{1} \mathrm{H}$ NMR Spectra of Three 2:1 Cobalt(III) Complexes of 1-(2-Carboxyphenyl)Azo-2-Naphthol. Dyes and Pigments, 57, 115-119. http://dx.doi.org/10.1016/S0143-7208(02)00119-5

[25] Hikara, T., Okada, Y. and Morita, Z. (2003) An Analysis of Azo-Hydrazonetautomerism of Reactive Azobenzene and Pyrazolinyl-Azo Dyes Using the Semiempirical Molecular Orbital PM5 Method. Dyes and Pigments, 61, 199-225.

[26] Wojciechowski, K. and Szymczak, A. (2007) The Research of the Azo-Hydrazone Equilibrium by Means of AM1 Method Basing on an Example of the Azo Dye-The Schäffer Salt Derivative. Dyes and Pigments, 75, 45-51. http://dx.doi.org/10.1016/j.dyepig.2006.05.016

\section{Submit or recommend next manuscript to SCIRP and we will provide best service} for you:

Accepting pre-submission inquiries through Email, Facebook, LinkedIn, Twitter, etc. A wide selection of journals (inclusive of 9 subjects, more than 200 journals)

Providing 24-hour high-quality service

User-friendly online submission system

Fair and swift peer-review system

Efficient typesetting and proofreading procedure

Display of the result of downloads and visits, as well as the number of cited articles Maximum dissemination of your research work

Submit your manuscript at: http://papersubmission.scirp.org/

Or contact cc@scirp.org 